\title{
Application of hydraulic press for testing powered roof prop supports
}

\author{
Piotr Kipczak ${ }^{1, *}$, and Krzysztof Władzielczyk $^{1}$ \\ ${ }^{1}$ AGH University, Department of Machinery Engineering and Transport, al. Mickiewicza 30, 30-059 \\ Krakow, Poland
}

\begin{abstract}
The report presents the possibility of using press forging, used in a smelter in the crushing and forming steel ingots processes, to the operation of compression powered roof supports. Press have been redeveloped which is to construct, to produce and to exchange handles so that they can be mounted in these housing racks in an upright position. Given the capability of measured quantities, measurement procedure and methodology of the study. There were presented some exemplary results of the tests.
\end{abstract}

\section{Introduction}

The necessity to eliminate hazards and to secure the performance of works in underground mining excavations are very important scientific and technical problems, requiring innovative and responsible theoretical and practical solutions. The geological complexity of the rock layers, but also the accumulation of the initial energy of the rock gravity deformation caused by the forces of gravity is of great importance for the safety of mining works $[6,8]$. This is related to the increasingly deteriorating mining conditions prevailing on the mining walls. The dependence of the rock mass on the mechanized obuszowa during shocks and rock bursts can be explained by the so-called "Rock mass model", the scheme of which is shown in Figure 1 [1,9] Two layers of rock can be distinguished in the rock massif. The lower one is a direct ceiling, which forms the most densely fractured layers, passing, in case of exploitation for a heart attack, into a chaotic debris in the goaf. The upper part is the main ceiling, composed of heavily cracked layers, preserving some form of geometrical continuity in the goaf. The shape of the relaxed rock mass has a significant impact on the increase of the rock mass pressure in a given mining excavation. The correct operation, adapted to the existing mining and geological conditions of the housing depends mainly on the safety of the crew, and in the further consequence the rhythmicity of the mining process. The problem of housings designed for work in difficult mining and geological conditions, and especially in thawed deposits, is of particular importance $[1,5$, 7]. This is a very serious problem because currently about $50 \%$ of active hard coal mining walls in Poland are exploited in rock blast beds $[6,8]$. The existing situation causes that the hydraulic powered housings used in these conditions should have appropriate safeguards

\footnotetext{
*Corresponding author: kipczak@agh.edu.pl
} 
allowing for taking over dynamical loads occurring in time of bumps [4, 9]. At present, there are workplace tests simulating the real conditions prevailing in the face, aiming at testing new solutions for the protection of hydraulic racks [2, 3]. Bearing in mind the conditions prevailing in the excavation, hydraulic industrial presses with a pressure force of $25 \mathrm{MN}[2]$ were used for testing hydraulic racks of mechanized housings working in rockblast beds.

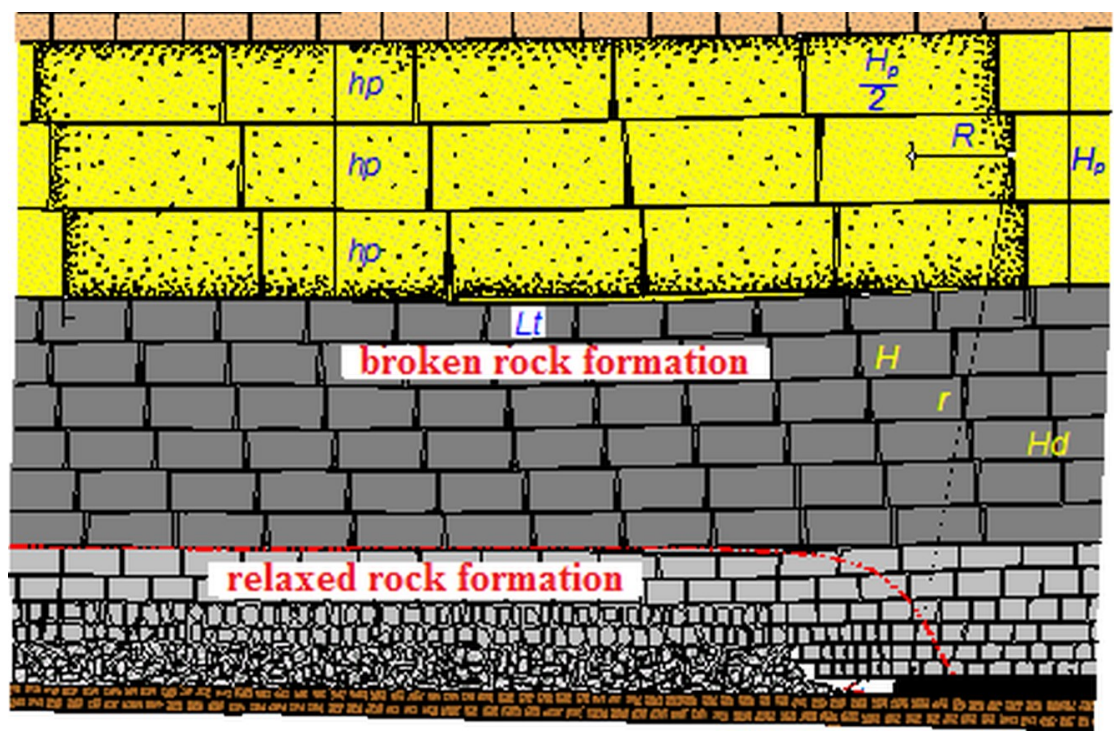

Fig. 1. Schematic disturbed rock wall around the bump at risk [1].

\section{Description of the hydraulic press}

Hydraulic press has standard equipment for a crushing and forging ingot, so it became necessary to make the corresponding fixture for testing hydraulic props. The basic starting point to create a table and handles the upper anvil, which will implement the process of subsidence of the r. Using the holes and guides technology of the hydraulic press (Fig. 2) mounting rack brackets are designed to serve as a mounting rack in the roof bar and floor. For research purposes carrying large cylinders, based on certain assumptions, have been adapted for hydraulic press. The task of the press was to put pressure on the test cylinder (Fig. 3) to determine the value of opening and closing pressure relief valve. Basic technical assumptions as stated in relation to the test bench, the opportunities for the position:

- the maximum compressive force is 20 [MN]

- research hydraulic props with length within the limits of $1.0-3.5[\mathrm{~m}]$

- research hydraulic props stand within diameters of 0.1-0.6 m

- supply pressure stands from 30 to $50 \mathrm{MPa}$

- feed pumps actuators working cylinder $>801 / \mathrm{min}$

The test stand used for the study consists of rails, fixed beams, sliding beams, a table and working actuators. Supporting structure (four slides) followed by moving sliding beams, using the actuators generate force is a very important arrangement, because of the possibility of adjusting the pressure and velocity of falling working actuators. The sliding and moveable beams of the top move, depending on the desired strength and speed falling, three cylinders $\varnothing 650 \mathrm{~mm}$. An important element of the press is a sliding table, allowing easy assembly of the actuator in the handle and it can slip in under the anvil mounted on the 
sliding beam. Actuator mounted fixtures can be seen on Figure 2. Upper handle is mounted in an anvil slot, while the bottom bracket is in the sliding table. The task of the handles was to generate pressure in the cylinder axis.

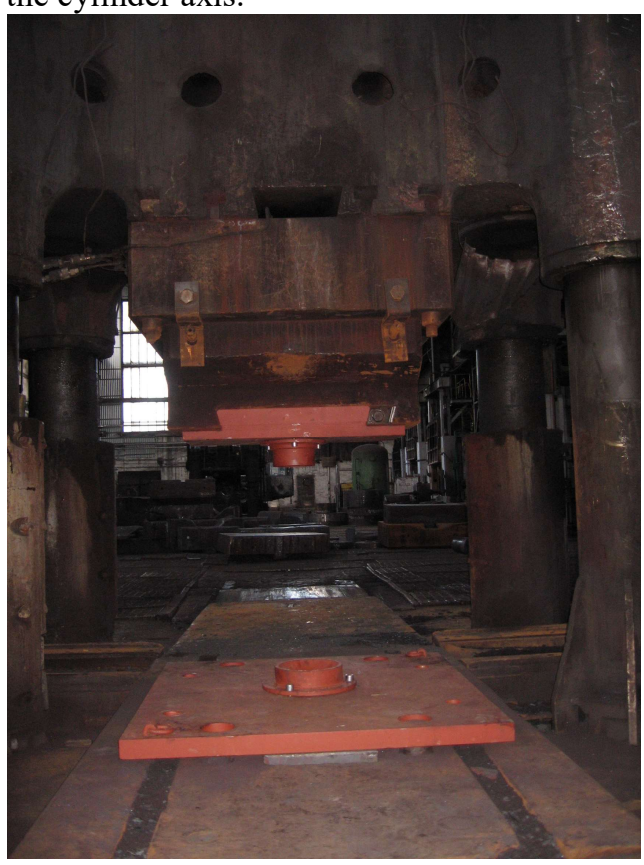

Fig. 2. View mounted handles [2].

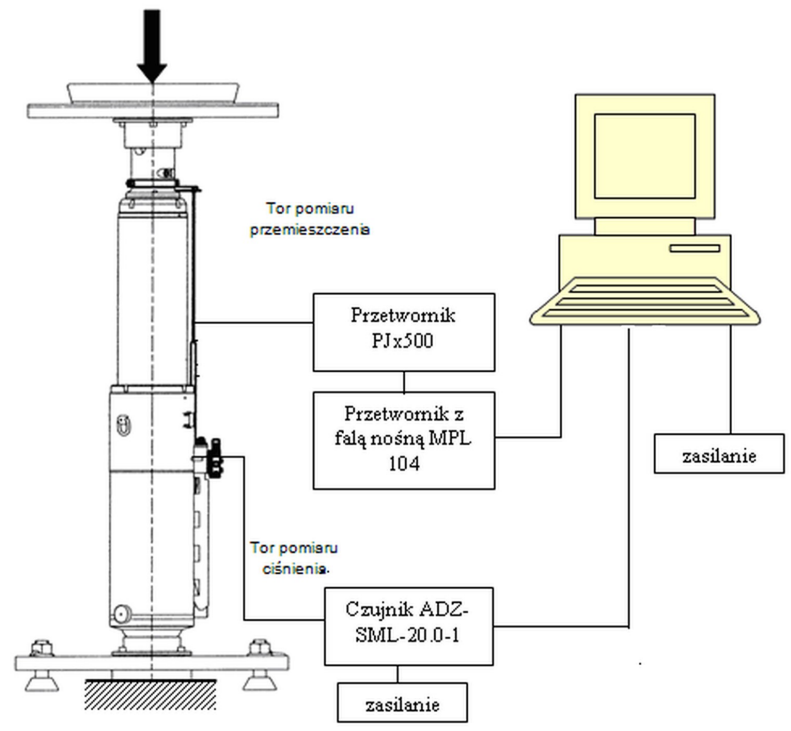

Fig. 3. Schematic of the measurement system used in the study [2]. 


\section{The research place}

The research place consisted of the following three systems:

- mechanical system visible on Figure 2; hydraulic press with handles,

- hydraulic power system and venting stands (Fig. 4) - which made the process of venting and power stand in during the experiment. The composition of this system included: hydraulic power unit, consisting of pumps, valves and system pressure relief valve and a switch turns of the electric motor. The switch turns allow you to quickly change the direction of flow of the emulsion, either for Spreading stand or the purpose of plundery. During the operation, the unit being supplied with hydraulic reservoir was disconnected and a pump connected to tank (a barrel) with an emulsion. Collection of emulsions was made after cleaning it through the filter mesh $100[\mu \mathrm{m}]$. The unit while adjusting the bypass valve and on the bench is presented in the Fig.4 and Fig.5. In order to vent and control the operation of tested hydraulic cylinders, the powering them up was done through the hydraulic unit shown in Figure 4 with a 1.0 grade gauge to control pressure.

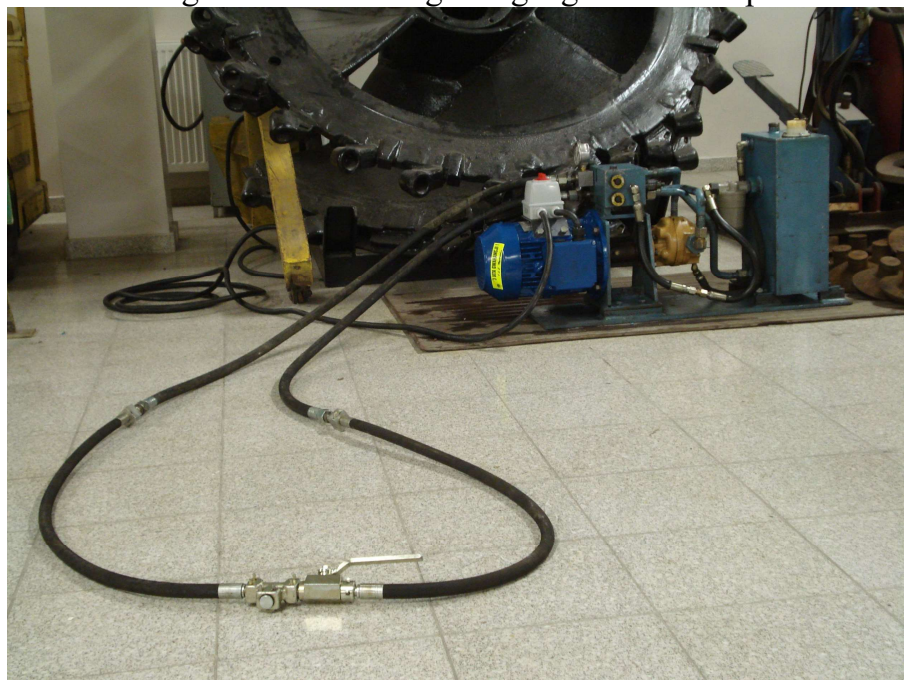

Fig. 4. Adjusting the settings of a hydraulic drive for supplying stand [2]

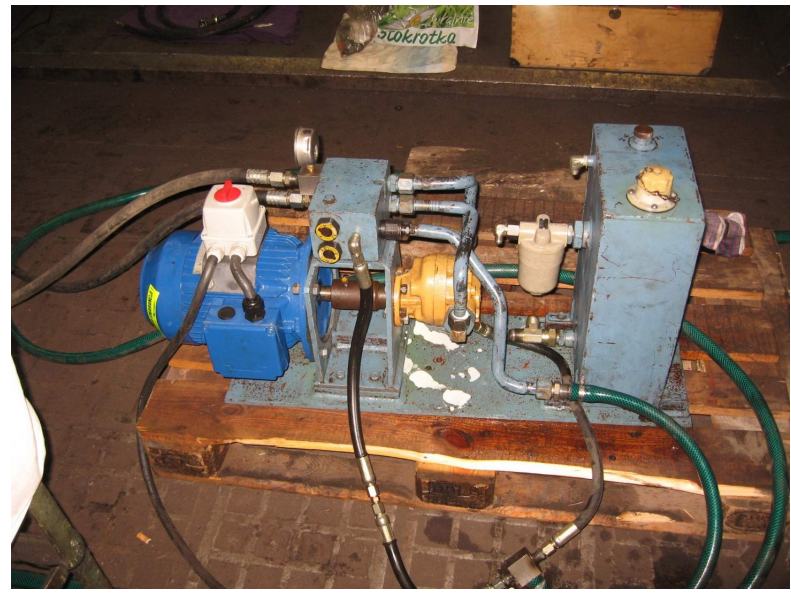

Fig. 5. Hydraulic drive on the test bench in HSW Stalowa Wola [2] 
- measuring system consisted of two parts, ie mechanical and electrical ones. Mechanical part consisted of pre-designed and built equipment for mounting sensors (Fig. 6) and a simple hydraulic components for directing a stream of emulsion to the over or sub-crushing zones, for either prizing apart or plundery of the stand or to shut off the flow allowing the load rack. For the implementation of the procedures was used hydraulic valve connected to a specific constructed shut-off valve. The measurement of electrical parts included:

- Inductive displacement meter with amplifier,

- Inductive pressure transducer with amplifier,

- Voltage divider,

- Measuring computer with sampling time 0.001 [s].

Schema shows the measuring system used Fig.6, and this picture shows a fully armed measuring stand with the mechanical and electrical elements. The stand was used to determine the pressure of opening and closing the safety valves tested at different testing options of the actuator, in order to verify the new approach of a new design valve for useful actuators with large stability. Implementation of the basic assumptions in relation to the research place, were concerning:

- the maximum compressive force is 20 [MN],

- research of hydraulic props with lengths within the limits of $1.0-3.5$ [m]

- research of hydraulic props diameters within 0.1-0.6 m

- the pressure for stands from 1930 to $1950 \mathrm{MPa}$

- efficiency of the pumps connected to working actuators $>801 / \mathrm{min}$

The measurement system, whose scheme is presented in Fig 3, consisted of a pressure sensor CL-1L, range up to $100[\mathrm{MPa}]$ and sensitivity of $2.67[\mathrm{mV} / \mathrm{MPa}]$ with a maximum value of $10 \%$ overload. Measurement of displacement was made by using an inductive displacement sensor type PJx 500 with a measuring range of $\pm 500[\mathrm{~mm}]$ and with a maximum nonlinearity of $0.41 \%$.

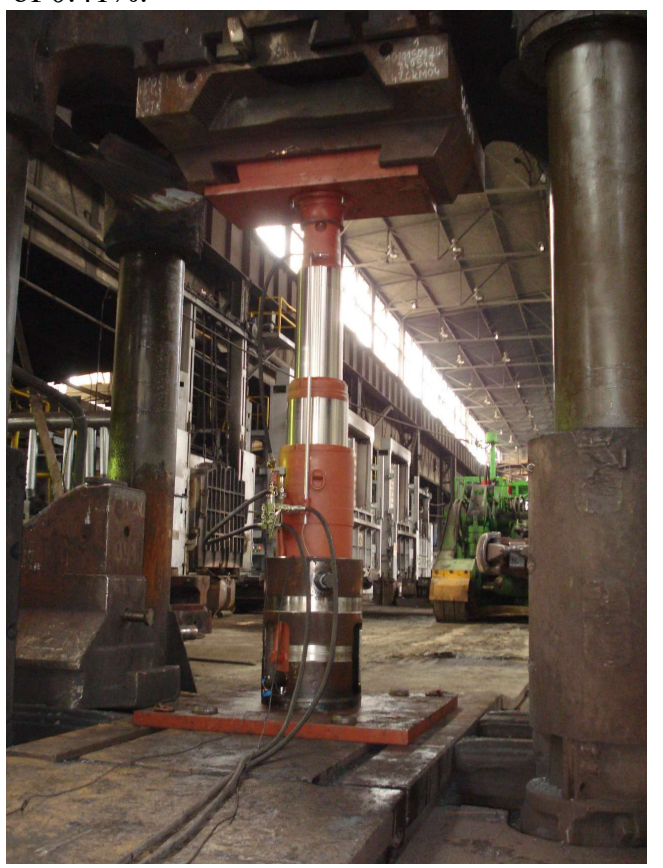

Fig. 6. Vented and fully armed stand before you try squeezing [2] 


\section{The procedure of preparing a hydraulic press for testing hydraulic racks}

In order to carry out tests on hydraulic stands, it was necessary to create a procedure for adapting the hydraulic press to the tests performed. After the analysis of the structure of the hydraulic press, its technical parameters, the method of controlling the work of the press and the tooling installed on the press, the procedure of preparing the hydraulic press for the individual stages of testing the stands was adopted. The procedure was as follows:

1. disassembly of anvils and working handles of the standard equipment of the press, depending on the construction of the tested rack,

2. assembly of anvils and working handles depending on the construction of the tested stand,

3. checking the correctness of the assembly of the press tooling and the reliability of mounting the tested rack in mounted holders,

4. performing a preliminary test of the anvil slide for specific values of the sliding velocity.

\section{Measured quantities and methodology of conducting tests}

The measurements measured during the racks were:

- pressure prevailing under the piston of the external core as a function of time,

- displacement of the inner core piston rod as a function of time.

The tests were carried out in such a way that before starting the tests, after ejecting the hydraulic stand and bleeding its hydraulic system, the rack was put under the anvil of the hydraulic press using a sliding table. The next step was to eliminate the misalignment of the actuator axis with the anvil axis and closing the valve that cuts the stand power supply. The next stage of the racks' tests was to measure their sliding speed for certain values of the anvil's fingerprints. After making a series of measurements, the actuator was extended to complete the operating medium in the stand before the next test. Measurements of a given rack were carried out until the predetermined range of rack sliding speeds was exhausted, which predicted lowering the upper press anvil at speeds of $10 \%, 20 \%, 30 \%, 40 \%, 50 \%$, $60 \%, 70 \%, 80 \%, 90 \%$ and $100 \%$ of its maximum speed. At the rate of less than $10 \%$, the hydraulic systems of the press were not allowed.

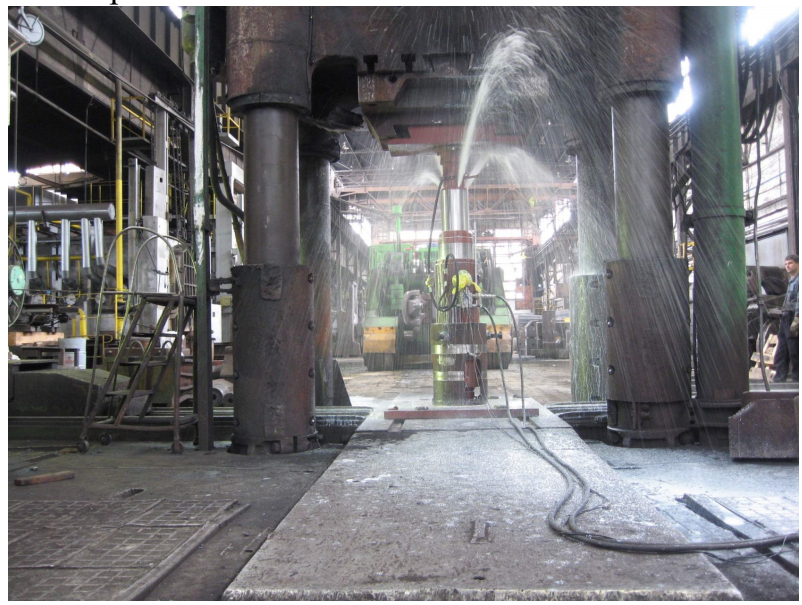

Fig. 7. View ram compression during measurement [2]

The speed of lowering the anvil and thus the speed with which the inner core was pressed into the external core displaced from it through the bleed valve was determined by 
setting the overflow valves with certain values controlled from the hydraulic press work station. The set ranges were determined each time for a specific measuring series of a given type of hydraulic stand. After carrying out a full series of tests of the hydraulic rack, it was replaced with another type of stand, for which a further examination was carried out according to the methodology presented above.

\section{Summary}

Presented in the paper, methodology of testing racks of mechanized housings of high load capacity with the use of hydraulic presses with high nominal pressures allows obtaining reliable results of testing the working parameters of the stands. The implementation of rack tests in their full scope of work requires only minor modifications of the press construction involving the assembly of appropriate hydraulic rack mounts on the press using already existing mounting holes. Thanks to this, it is possible to securely immobilize the hydraulic rack during its testing, as well as easy assembly and disassembly of the stand after the tests, Fig. 6.

It is also worth paying attention to the fact of ensuring full safety of testing the racks on the hydraulic press in question. As it can be seen in Fig. 7, the design of the hydraulic press provides free access to the tested rack, and the considerable space around the press eliminates the dangers resulting from possible breakage of the stand during the tests.

Another advantage of using hydraulic presses to test the roofs of mechanized housings is the possibility of precise adjustment of the pressure force of the press, and thus the load on the tested rack. Thanks to this, it is possible to draw up a very precise working characteristic of the tested stand in the form of an appropriate graph. Examination of the stands on the hydraulic press also allows to determine the operation and opening pressure of quick-return valves mounted in hydraulic racks, intended for mechanized roofs working in excavations threatened by rock-bumps. Verification of the operation of these valves is extremely important from the point of view of work safety of the mining wall. Fig. 8 presents an example of the operation characteristics of the DN12 quick-release valve obtained during the TAGOR N-142 hydraulic rack test.

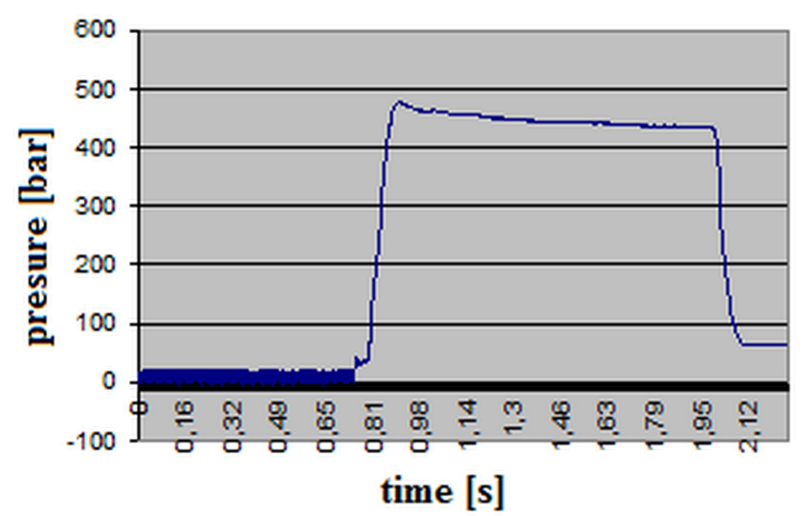

Fig. 8. Measurement of the displacement of $40 \%$ [2]

\section{References}

1. A. Biliński, T. Kostyk, PG, 3 (2014)

2. The test stand Forge Stalowa Wola (Stalowa Wola, Raport, 2014) (not published) 
3. J. Marianowski, P. Kipczak, A. PG, 67 (2011)

4. D. Szurgacz, Mining Science, 22 :Special Issue 2, 171-179 (2015)

5. L. Doległo, J. Gil, K. Stoiński, MG, 4 (2013)

6. K Krauze, PG, 63(11), 2007

7. T. Łagoda, Transport, 4:22 (2013)

8. S. Prusek, Stateczność wyrobisk ścianowych podczas eksploatacji pokładów wegla kamiennego z zawałem skat stropowych (Główny Instytut Górnictwa, Katowice, 2016)

9. D. Szurgacz, A. Kasprusz, Prace naukowe GIG. Górnictwo i Środowisko, 3, 89-99 (2011) 